\title{
AS ELITES PARLAMENTARES SUL-AMERICANAS E AS NTICS: PERFIL SOCIOPOLÍTICO E USO DA WEB POR DEPUTADOS E SENADORES DO BRASIL, ARGENTINA, CHILE, PARAGUAI, URUGUAI E VENEZUELA ${ }^{1}$
}

\author{
María Alejandra Nicolás ${ }^{2}$ \\ Sérgio Soares Braga ${ }^{3}$
}

- Enviado em 09/08/2015

- Aprovado em 18/09/2015

\section{RESUMO}

O objetivo deste artigo é apresentar os resultados da nossa pesquisa sobre o uso da internet pelas elites parlamentares que ocupam as casas legislativas nacionais no período de maio a junho de 2009 no Brasil, Argentina, Uruguai, Venezuela, Paraguai e Chile. Para tal fim, coletamos dados sobre e analisamos ao todo 1501 parlamentares de seis países e 11 casas legislativas. A partir dos dados coletados, a disponibilidade de informações sobre perfil socioeconômico e comportamento político é bastante desigual entre as diferentes casas legislativas, destacando-se os portais das Câmaras dos Deputados e do Senado do Brasil e do Chile como aqueles que obtiveram o melhor índice de desempenho em detrimento dos demais países.

Palavras-chave: Internet e Política. Elites Parlamentares Sul-Americanas. Graus de representação política.

\footnotetext{
${ }^{1}$ Dissertação defendida em 18 de setembro de 2009. Versão completa disponível na Biblioteca Digital da UFPR http://dspace.c3sl.ufpr.br:8080/dspace/handle/1884/21068

${ }^{2}$ Graduada em Ciência Política pela Universidad de Buenos Aires (UBA). Mestre em Sociologia pela Universidade Federal do Paraná (UFPR). Doutora em Sociologia pela Universidade Federal do Paraná, (UFPR). Professora do Curso de Administração Pública e Políticas Públicas, ILAESP/Universidade Federal da Integração Latino-Americana (UNILA). Endereço eletrônico: alejandranicolas@gmail.com
}

3 Sérgio Braga é professor do Programa de Pós-Graduação em Ciência Política da Universidade Federal do Paraná. É doutor em desenvolvimento econômico pelo IE/Unicamp, tendo realizado estágio pós-doutoral no ICS/Institute of Communication Studies da Universidade de Leeds onde realizou pesquisas sobre os impactos das tecnologias digitais na política brasileira (2013-2014). É um dos coordenadores do GT Ciberpolítica, Ciberativismo e Cibercultura na Anpocs. 


\section{INTRODUÇÃ̃ ${ }^{4}$}

Desde pelo menos meados dos anos 1990, os impactos da internet nas várias dimensões dos sistemas políticos contemporâneos, especialmente os sistemas políticos democráticos, têm sido objeto de uma vasta literatura. Há, inclusive, certo consenso entre os especialistas dedicados ao assunto na atualidade, especialmente na Europa e nos Estados Unidos, de que o ponto de partida para qualquer análise mais sistemática sobre o tema não deve ser pautado pela pergunta sobre se efetivamente a utilização destas tecnologias está se difundindo nas modernas democracias parlamentares, mas sim que tipo de impacto efetivo elas estão provocando nas múltiplas dimensões do funcionamento destes sistemas políticos. Especialmente nos países de democracia mais institucionalizada e estável, onde a reflexão sobre o tema está mais avançada, há um grande e crescente campo de estudos e pesquisas sobre os impactos das tecnologias digitais em geral e da internet em particular nas várias dimensões dos sistemas políticos. Com efeito, nos países mais desenvolvidos, os impactos da internet nos mais variados tipos de atores e instituições participantes dos "sistemas políticos virtuais" já foram objeto de estudos sistemáticos e "empiricamente orientados", especialmente nos países anglo-saxões. Apenas a título de exemplo, podemos mencionar a existência de um amplo conjunto de trabalhos sobre "e-gov e governo eletrônico" (Kakabadsshe et. al., 2003; Seifert \& Chung, 2009), ciberativismo e movimentos sociais (Weissberg, 2003; Schussman, 2004), partidos políticos (Rommele, 2003; Norris, 2003; Ward, Gibson \& Nixon, 2003), eleições e processos eleitorais (Bimber \& Davis, 2003) e órgãos legislativos e parlamentares (Schmitter et. al, 2003; Beetham, 2006, Braga, 2007).

Este artigo se insere, portanto, no contexto da proliferação em escala internacional dos estudos que analisam a relação entre as tecnologias digitais e os processos de representação política (em geral) e as repercussões da internet sobre as atividades dos órgãos legislativos e sobre o comportamento das elites parlamentares (em particular) sob a ótica mais estrita da sociologia e da ciência política. Tem como objetivo principal avaliar o uso da internet pelas elites políticas que ocupam as casas legislativas nacionais em seis países da América do Sul (Argentina, Brasil, Chile,

\footnotetext{
4 A presente investigação foi desenvolvida no grupo de estudos "Democracia, Instituições Políticas e Novas Tecnologias", do departamento de Ciências Sociais da Universidade Federal do Paraná, e no contexto da pesquisa intitulada "Representação política, elites parlamentares brasileiras e as TICs: perfil sociopolítico, uso da internet e percepções do processo de modernização dos órgãos parlamentares pelos senadores, deputados federais e deputados estaduais brasileiros (2007-2010)", coordenada por Sérgio Braga e financiada pelo CNPq (Edital Humanas/Sociais Aplicadas).
} 
Paraguai, Uruguai e Venezuela) ${ }^{5}$ nos vários níveis em que se dá esse uso. A partir deste objetivo de ordem geral, elaboraremos um indicador quantitativo para mensurar o grau de disponibilidade das informações necessárias à caracterização dos perfis sociopolíticos dos parlamentares nas casas legislativas, desenvolvendo metodologia aplicada em outros estudos (Braga \& Nicolás, 2008).

Para cumprir estes objetivos, organizaremos nossa exposição da seguinte forma: (1) inicialmente, definiremos o universo empírico pesquisado e o contexto institucional "offline" dos diferentes países analisados, bem como esclareceremos alguns aspectos do método que utilizaremos para compor os indicadores visando a mensuração do uso da web pelos atores observados; (2) em seguida, avaliaremos as informações contidas nos websites das assembleias examinadas sobre o "perfil social" dos parlamentares, tantos de seus "atributos inatos", quanto de seus atributos "adquiridos", sobre a trajetória política pregressa dos deputados e senadores, ou seja, sobre sua atuação ou "socialização" política antes de assumirem os mandatos nas casas legislativas na legislatura em tela, e sobre aqueles itens que julgamos mais relacionadas ao "comportamento político" dos parlamentares, tanto aqueles que podem ser acessados diretamente pelo cidadãointernauta através dos perfis individuais dos mesmos disponíveis nos sites das casas de representantes, quanto aquelas que estão acessíveis exclusivamente através dos websites parlamentares; (3) por fim, na parte final do capítulo, analisaremos o uso que os deputados e senadores fazem da internet, cotejando os resultados de nossa pesquisa com os de outros estudos produzidos em outros países sobre a temática, a fim de dar início a uma reflexão mais sistemática sobre o uso dos websites pelos parlamentares sul-americanos.

\section{O UNIVERSO EMPÍRICO DE PESQUISA E A METODOLOGIA EMPREGADA: AS ELITES PARLAMENTARES DA AMÉRICA DO SUL E A INTERNET}

A primeira dimensão de nossa metodologia se consistiu em examinar os websites dos órgãos legislativos dos países indicados e as informações individuais neles contidas sobre cada parlamentar, a fim de verificar se havia nestes websites ou portais informações sobre o perfil social (atributos inatos e adquiridos $)^{6}$ das elites parlamentares nele representadas, sobre a socialização ou

\footnotetext{
${ }^{5}$ A pesquisa empírica foi realizada entre maio e junho de 2009.

${ }^{6}$ Para a distinção entre atributos inatos e adquiridos, cf. Keller (1967). 
trajetória política prévia e sobre variáveis que pudessem avaliar seu "comportamento político", dentro e fora dos órgãos parlamentares.

Algumas características do universo empírico de nossa pesquisa estão sintetizadas na tabela a seguir. Coletamos dados sobre e analisamos ao todo 1501 parlamentares de seis países e 11 casas legislativas, examinamos o uso que os mesmos fazem da internet e alguns atributos de seu perfil social e trajetória política anterior. Utilizamos exclusivamente as fontes disponíveis nos websites das casas legislativas para coletar as informações. A distribuição agregada dos parlamentares por partidos políticos no período da pesquisa e consolidação dos dados é dada pela tabela abaixo

Tabela 1: Distribuição partidária dos deputados e senadores (agregado - maio/junho de 2009)

\begin{tabular}{|c|c|c|c|c|c|c|c|c|c|c|c|c|c|}
\hline & & $A r C D$ & $\operatorname{ArSN}$ & $B r C D$ & BrSN & $C h C D$ & ChSN & $P g C D$ & $P g S N$ & UrCD & UrSN & $V e C D$ & Total \\
\hline & Partidos políticos & $\%$ & $\%$ & $\%$ & $\%$ & $\%$ & $\%$ & $\%$ & $\%$ & $\%$ & $\%$ & $\%$ & $\%$ \\
\hline 1 & Justicialista & 47,7 & 54,2 & & & & & & & & & & 10,7 \\
\hline 2 & Unión Cívica Radical & 9,8 & 11,1 & & & & & & & & & & 2,2 \\
\hline 3 & PMDB & & & 18,5 & 25,9 & & & & & & & & 7,7 \\
\hline 4 & DEM & & & 10,9 & 19,8 & & & & & & & & 4,8 \\
\hline 5 & PP & & & 7,8 & 1,2 & & & & & & & & 2,7 \\
\hline 6 & PR & & & 8,4 & 3,7 & & & & & & & & 3,1 \\
\hline 7 & PSDB & & & 11,3 & 16,0 & & & & & & & & 4,7 \\
\hline 8 & PT & & & 15,4 & 14,8 & & & & & & & & 6,1 \\
\hline 9 & P.D.C. & & & & & 13,3 & 13,2 & & & & & & 1,4 \\
\hline 10 & P.P.D. & & & & & 16,7 & 5,3 & & & & & & 1,5 \\
\hline 11 & P.S. & & & & & 11,7 & 18,4 & & & & & & 1,4 \\
\hline 12 & R.N. & & & & & 16,7 & 18,4 & & & & & & 1,8 \\
\hline 13 & U.D.I. & & & & & 27,5 & 23,7 & & & & & & 2,8 \\
\hline 14 & ANR & & & & & & & 37,5 & 33,3 & & & & 3,0 \\
\hline 15 & PLRA & & & & & & & 36,3 & 31,1 & & & & 2,9 \\
\hline 16 & PUNACE & & & & & & & 18,8 & 20,0 & & & & 1,6 \\
\hline 17 & Frente Amplio & & & & & & & & & 52,5 & 54,8 & & 4,6 \\
\hline 18 & Partido Colorado & & & & & & & & & 10,1 & 9,7 & & 0,9 \\
\hline 19 & Partido Nacional & & & & & & & & & 36,4 & 35,5 & & 3,1 \\
\hline 20 & PSUV & & & & & & & & & & & 85,5 & 9,5 \\
\hline \multirow[t]{3}{*}{21} & Outros & 42,6 & 34,7 & 27,7 & 18,5 & 14,2 & 21,1 & 7,5 & 15,6 & 1,0 & 0,0 & 14,5 & 23,5 \\
\hline & Total\% & 100,0 & 100,0 & 100,0 & 100,0 & 100,0 & 100,0 & 100,0 & 100,0 & 100,0 & 100,0 & 100,0 & 100,0 \\
\hline & Total/N & 256 & 72 & 513 & 81 & 120 & 38 & 80 & 45 & 99 & 31 & 166 & 1501 \\
\hline
\end{tabular}

Fonte: NPDIP/Núcleo de Pesquisa Democracia, Instituições Políticas e Novas Tecnologias 
Pela tabela acima podemos verificar que há características bastante diversas, entre os diferentes sistemas políticos e partidários dos vários países, variando desde um presidencialismo centralizado com um sistema partidário dominado por um partido com mais de $80 \%$ da representação parlamentar, como é o caso da Venezuela, até sistemas partidários mais fragmentados, como é o caso da Argentina e do Brasil, passando por sistemas partidários menos fragmentados e mais sedimentados nos órgãos parlamentares, como é o caso do Chile, Paraguai e Uruguai. Ao todo foram computados ao longo do período da pesquisa 105 partidos políticos representados nos 11 órgãos parlamentares examinados, sendo que os partidos mais relevantes encontram-se mencionados na tabela acima.

Como é enfatizado por estudos recentes (Zittel, 2003, Leston-Bandeira, 2007), um importante fator a ser levado em conta para um entendimento mais abrangente do uso das tecnologias digitais pelos atores integrantes dos diferentes sistemas políticos são as características institucionais que estruturam o funcionamento de tais sistemas.

Observamos que o arcabouço institucional dos seis países - Argentina, Brasil, Chile, Paraguai, Uruguai e Venezuela - apresentam similitudes em vários aspectos, porém, possuem diferenças substantivas que merecem ser destacadas.

O trajeto percorrido pelos países após o fim dos regimes autoritários revela traços compartilhados ${ }^{7}$. Nenhum país escapou de introduzir modificações importantes em seus sistemas eleitorais, seja para os cargos executivos ou legislativos, inclusive algum deles introduzindo reformas radicais. Uma realidade que, de maneira geral, pode-se constatar é a de que o número efetivo de partidos aumentou nestes países e, por consequência, os legislativos encontram-se mais fragmentados e os governos passaram a recorrer a gabinetes de coalizão. Estes traços têm modificado as relações entre os poderes, assim como afetado o comportamento dos atores relevantes no processo decisório.

Todos os países sob análise possuem sistemas de governo presidencialistas. Uma das visões interpretativas que dominaram nos fins da década de 1980 e início dos anos 1990 partia do suposto que os presidencialismos na América do Sul teriam pouca possibilidade de consolidar-se, devido às

\footnotetext{
${ }^{7}$ Excetuando a Venezuela, todos estes países passaram por ditaduras militares entre as décadas de 1960 e 1980 e por bem-sucedidas (embora um tanto quanto conturbadas) transições para a democracia após a crise destes regimes.
} 
suas características institucionais específicas, particularmente por combinar um chefe do Executivo com fortes poderes de agenda com sistemas partidários com elevados índices de fragmentação ${ }^{8}$.

Algumas características institucionais do universo empírico de nossa pesquisa estão sintetizadas no quadro abaixo:

Quadro 2: Características institucionais dos países sul-americanos

\begin{tabular}{|c|c|c|c|c|c|c|c|c|c|}
\hline Países & $\begin{array}{l}\text { Sistema } \\
\text { Político }\end{array}$ & $\begin{array}{l}\text { Divisão } \\
\text { Política }\end{array}$ & $\begin{array}{c}\text { Tipo de } \\
\text { Cameralismo }\end{array}$ & \multicolumn{2}{|c|}{ Sistema Eleitoral } & \multicolumn{2}{|c|}{ Número de membros } & \multicolumn{2}{|c|}{ Tipo de Lista } \\
\hline Argentina & Presidencialismo & Federalismo & Bicameralismo & $\begin{array}{l}\text { Representação } \\
\text { Proporcional }\end{array}$ & $\begin{array}{l}\text { Majoritário com } \\
\text { correçẫo } \\
\text { proporcional }\end{array}$ & 256 & 72 & Fechada & $\begin{array}{c}\text { Segunda } \\
\text { lista recebe a } \\
\text { terceira } \\
\text { cadeira }\end{array}$ \\
\hline Chile & Presidencialismo & Unitarismo & Bicameralismo & $\begin{array}{c}\text { Majoritário com } \\
\text { correçăo proporcional }\end{array}$ & Majoritário & 120 & 47 & Majoritária & Majoritária \\
\hline Paraguai & Presidencialismo & Unitarismo & Bicameralismo & $\begin{array}{l}\text { Representação } \\
\text { Proporcional }\end{array}$ & $\begin{array}{l}\text { Representação } \\
\text { Proporcional }\end{array}$ & 80 & 45 & Fechada & Fechada \\
\hline Venezuela & Presidencialismo & Federalismo & Unicameralismo & $\begin{array}{c}\text { Misto de correção. } 60 \\
\% \text { dos distritos } \\
\text { uninominais }\end{array}$ & NP & 166 & NP & Fechada & NP \\
\hline
\end{tabular}

Fonte: Anastasia et al. (2004). Elaboração da autora

NP: Não possui.

Três países onde os parlamentares da nossa pesquisa atuam são federações: Argentina, Brasil e Venezuela. Os restantes, Chile, Paraguai e Uruguai são unitários. Os países federativos são normalmente bicamerais, adotando a Câmara Alta (Senado) como foro de representação das unidades territoriais. A Venezuela até 1999 se constituía num país que poderia ser incluído na regra anterior, porém, a partir da Constituição desse ano passou a contar com apenas uma Câmara, composta de 166 membros, a Assembleia Nacional.

\footnotetext{
${ }^{8}$ Os principais propugnadores dessa tese no início da década de 1990 foram o cientista político espanhol Juan Linz e o politólogo norte-americano Scott Mainwaring. Cf. Mainwaring \& Shugart (1993). Não obstante estes prognósticos negativos, tais regimes se estabilizaram por tempo suficiente para sofrer o impacto das NTICs ao longo do século XXI, com a realização de eleições regulares e alternância de poder entre correntes distintas. Cf. a respeito disso o trabalho organizado por Fátima Anastasia e Fabiano Santos (Anastasia et al., 2004).
} 
Em relação aos sistemas eleitorais dos seis países analisados, todos sofreram modificações no desenho da engenharia institucional a partir dos anos 1990: até então todos adotavam o sistema de representação proporcional. Argentina e Brasil adotam o sistema proporcional para a Câmara dos Deputados e o sistema majoritário para o Senado. Paraguai e Uruguai utilizam o sistema proporcional em ambas as câmaras. Chile utiliza o sistema majoritário. Venezuela possui um sistema eleitoral misto. Segundo Anastasia et al. (2004), Chile e Venezuela possuem os sistemas eleitorais menos proporcionais. $\mathrm{O}$ desenho dos sistemas eleitorais tende a afetar a composição dos legislativos. Sistemas mais desproporcionais criam "maiorias fabricadas" que reduzem, de modo artificial, o número de partidos efetivos, já que as distorções sempre favorecem os partidos maiores (Oliveira, 2006, p. 311).

Com relação ao tipo de lista, todos os países, com exceção do Brasil e do Chile, possuem lista fechada. Este tipo de lista partidária para a escolha dos candidatos nas eleições favorece a centralização partidária. Na maioria destes casos, os líderes partidários controlam as listas e, por exemplo, no caso da Argentina os primeiros colocados na lista são os que serão eleitos. No entanto, nos casos de Brasil e Chile que adotam lista aberta e majoritária, os líderes controlam as listas, mas não possuem a prerrogativa de ordená-las. O Brasil utiliza a lista aberta: "os partidos apresentam uma lista de candidatos sem definir a ordem de preferência sendo que cada eleitor dá seu voto para um candidato ou partido e as cadeiras obtidas pelo partido são ocupadas pelos candidatos mais votados" (Nicolau, 2002: p. 223). Outra característica importante dos sistemas eleitorais do Brasil e do Chile é o fato de serem fortemente personalizados e "centrados no candidato", ao contrário dos demais países, onde os partidos são mais fortes na arena eleitoral. Deve-se sublinhar que tal fator de ordem institucional pode ser um importante elemento condicionante dos padrões de uso da web pelos deputados e senadores destes países.

A partir dos dados do universo de pesquisa definido na tabela 1 construímos uma planilha com todos os parlamentares atuantes nas casas legislativas, bem como com as frequências das variáveis pesquisadas nos sites legislativos dos diversos órgãos parlamentares. Apenas a título de exemplo, enumeramos na tabela abaixo o percentual de algumas das principais variáveis "brutas" que usamos para construir as planilhas, bem como derivar as informações e os gráficos apresentados a seguir. 
Tabela 2: Informações disponíveis na web sobre as elites parlamentares da América do Sul (maio de 2009)

\begin{tabular}{|c|c|c|c|c|c|c|c|c|c|c|c|c|}
\hline \multicolumn{13}{|c|}{ I) PERFIL SOCIAL } \\
\hline & ArCD & ArSN & $\mathrm{BrCD}$ & BrSN & ChCD & ChSN & $\overline{P g C D}$ & PgSN & UrCD & UrSN & $\overline{\mathrm{VeCD}}$ & Total \\
\hline Tem foto? & 99,6 & 100,0 & 99,6 & 97,5 & 100,0 & 100,0 & 100,0 & 100,0 & 91,9 & 96,8 & 88,6 & 97,8 \\
\hline Informa chefe de família: & 0,8 & 4,2 & 97,9 & 1,2 & 0,0 & 5,3 & 2,5 & 2,2 & 0,0 & 0,0 & 0,0 & 34,2 \\
\hline Informa data de nascimento? & 15,6 & 54,2 & 99,2 & 63,0 & 98,3 & 76,3 & 26,3 & 42,2 & 45,5 & 41,9 & 14,5 & 60,5 \\
\hline Informa estado civil? & 16,0 & 45,8 & 0,0 & 1,2 & 90,0 & 65,8 & 25,0 & 46,7 & 35,4 & 19,4 & 0,0 & 19,3 \\
\hline Informa local de nascimento & 11,3 & 50,0 & 0,2 & 100,0 & 0,0 & 31,6 & 28,8 & 33,3 & 36,4 & 32,3 & 12,7 & 17,6 \\
\hline IS/Infor. Satifs. sb escolaridade? & 24,2 & 66,7 & 83,2 & 81,5 & 86,7 & 81,6 & 35,0 & 48,9 & 44,4 & 29,0 & 51,2 & 61,7 \\
\hline IS sb instituição que fez CS & 19,1 & 59,7 & 78,9 & 0,0 & 78,3 & 73,7 & 21,3 & 35,6 & 25,3 & 9,7 & 0,6 & 45,4 \\
\hline IS sb ano que se formou? & 13,3 & 33,3 & 67,6 & 0,0 & 19,2 & 18,4 & 10,0 & 8,9 & 7,1 & 9,7 & 0,6 & 30,5 \\
\hline IS sb atividade profissional? & 23,8 & 72,2 & 85,2 & 82,7 & 98,3 & 84,2 & 75,0 & 42,2 & 46,5 & 25,8 & 53,6 & 65,9 \\
\hline \multicolumn{13}{|c|}{ II) TRAJETORIA POLITICA } \\
\hline IS sb entrada na política & 26,2 & 73,6 & 82,1 & 77,8 & 100,0 & 84,2 & 30,0 & 51,1 & 53,5 & 48,4 & 57,8 & 64,4 \\
\hline IS sb período de entrada & 24,2 & 69,4 & 96,9 & 0,0 & 76,7 & 63,2 & 23,8 & 44,4 & 49,5 & 45,2 & 0,0 & 55,1 \\
\hline IS sb local de entrada & 16,0 & 51,4 & 82,3 & 0,0 & 3,3 & 13,2 & 10,0 & 13,3 & 29,3 & 22,6 & 0,0 & 37,2 \\
\hline IS sobre primeiro mandato & 27,3 & 79,2 & 96,5 & 0,0 & 97,5 & 76,3 & 22,5 & 44,4 & 48,5 & 41,9 & 0,0 & 57,8 \\
\hline Dest. $\mathrm{p} /$ mandatos legislativos & 14,8 & 54,2 & 100,0 & 0,0 & 100,0 & 100,0 & 100,0 & 100,0 & 48,5 & 41,9 & 0,6 & 62,3 \\
\hline IS sobre mandato legislativo & 25,0 & 70,8 & 95,1 & 82,7 & 100,0 & 78,9 & 15,0 & 48,9 & 48,5 & 41,9 & 54,2 & 67,0 \\
\hline Destaque p/cargo executivo & 15,6 & 59,7 & 45,2 & 0,0 & 21,7 & 34,2 & 13,8 & 31,1 & 40,4 & 38,7 & 0,0 & 28,7 \\
\hline IS cargo administrativo & 18,8 & 66,7 & 66,1 & 0,0 & 21,7 & 44,7 & 12,5 & 31,1 & 42,4 & 38,7 & 0,0 & 37,0 \\
\hline Destaque p/filiação & 3,5 & 2,8 & 86,9 & 0,0 & 1,7 & 5,3 & 0,0 & 6,7 & 2,0 & 9,7 & 0,0 & 31,2 \\
\hline IS sobre capital social & 8,6 & 20,8 & 49,5 & 0,0 & 3,3 & 7,9 & 7,5 & 20,0 & 36,4 & 22,6 & 0,0 & 23,7 \\
\hline IS sobre atividade intelectual & 10,5 & 27,8 & 21,2 & 0,0 & 0,0 & 21,1 & 5,0 & 6,7 & 0,0 & 0,0 & 0,0 & 11,4 \\
\hline \multicolumn{13}{|c|}{ III) COMPORTAMENTO POLÍTICO } \\
\hline Tem email? & 100,0 & 100,0 & 100,0 & 97,5 & 100,0 & 100,0 & 100,0 & 100,0 & 96,0 & 100,0 & 89,8 & 98,5 \\
\hline Informa gabinete? & 0,0 & 0,0 & 100,0 & 100,0 & 0,0 & 0,0 & 100,0 & 97,8 & 1,0 & 0,0 & 0,0 & 47,9 \\
\hline Informa website? & 3,5 & 1,4 & 15,6 & 100,0 & 35,0 & 65,8 & 0,0 & 0,0 & 57,6 & 58,1 & 0,6 & 20,9 \\
\hline Informa fone? & 100,0 & 100,0 & 100,0 & 100,0 & 100,0 & 100,0 & 100,0 & 100,0 & 91,9 & 32,3 & 0,6 & 87,1 \\
\hline Link para discursos & 100,0 & 0,0 & 99,4 & 100,0 & 0,0 & 0,0 & 100,0 & 0,0 & 100,0 & 100,0 & 0,6 & 70,5 \\
\hline Link p/votação nominal & 100,0 & 0,0 & 78,2 & 100,0 & 100,0 & 0,0 & 0,0 & 0,0 & 100,0 & 100,0 & 0,0 & 65,8 \\
\hline Presença em plenário & 100,0 & 0,0 & 100,0 & 0,0 & 100,0 & 0,0 & 0,0 & 0,0 & 0,0 & 0,0 & 0,0 & 59,2 \\
\hline Presença nas comissões & 0,0 & 0,0 & 100,0 & 0,0 & 0,0 & 0,0 & 0,0 & 0,0 & 0,0 & 0,0 & 0,0 & 34,2 \\
\hline Link para projetos & 100,0 & 100,0 & 100,0 & 100,0 & 100,0 & 100,0 & 100,0 & 100,0 & 100,0 & 100,0 & 0,6 & 86,5 \\
\hline Link para outras propos. & 0,0 & 100,0 & 97,3 & 100,0 & 100,0 & 0,0 & 0,0 & 100,0 & 0,0 & 0,0 & 0,0 & 54,4 \\
\hline Serviço de clipping & 0,0 & 0,0 & 0,0 & 100,0 & 0,0 & 0,0 & 0,0 & 0,0 & 0,0 & 0,0 & 0,0 & 5,5 \\
\hline Link p/requerimento & 0,0 & 0,0 & 72,9 & 100,0 & 100,0 & 0,0 & 0,0 & 0,0 & 0,0 & 0,0 & 0,0 & 38,3 \\
\hline Destaque p/cargo ocupado & 100,0 & 100,0 & 96,7 & 100,0 & 99,2 & 0,0 & 100,0 & 100,0 & 100,0 & 100,0 & 99,4 & 96,2 \\
\hline Link para verba indenizatória & 0,0 & 0,0 & 0,0 & 0,0 & 100,0 & 100,0 & 0,0 & 0,0 & 0,0 & 0,0 & 0,0 & 10,5 \\
\hline Inf. Sobre viagens & 100,0 & 0,0 & 0,0 & 0,0 & 100,0 & 0,0 & 0,0 & 0,0 & 0,0 & 0,0 & 0,0 & 25,0 \\
\hline Link para patrimônio & 0,0 & 0,0 & 0,0 & 0,0 & 100,0 & 0,0 & 0,0 & 0,0 & 0,0 & 0,0 & 0,0 & 8,0 \\
\hline Total\% & 100,0 & 100,0 & 100,0 & 100,0 & 100,0 & 100,0 & 100,0 & 100,0 & 100,0 & 100,0 & 100,0 & 100,0 \\
\hline Total/N & 256 & 72 & 513 & 81 & 120 & 38 & 80 & 45 & 99 & 31 & 166 & 1501 \\
\hline
\end{tabular}

Fonte: NPDIP 
Pela tabela acima, podemos observar que a quase totalidade dos parlamentares examinados disponibiliza e-mail para contato com a opinião pública e os cidadãos de uma maneira geral: dos 1501 parlamentares pesquisados, 98,5\% disponibilizam e-mails nas casas legislativas para o contato com os cidadãos, evidenciando que já se tornou um procedimento generalizado a disponibilização de correio eletrônico dos deputados e senadores. Entretanto, como veremos mais à frente, o mesmo não pode ser dito em relação aos recursos dos websites (institucionais ou pessoais) por parte dos parlamentares, pois uma porcentagem bastante inferior dos parlamentares destes países sul-americanos disponibiliza websites para divulgar suas atividades para a opinião pública .

Por outro lado, no tocante a informações sobre algumas dimensões do perfil social dos deputados e senadores, a distribuição das porcentagens é bastante heterogênea. Assim, enquanto alguns websites legislativos disponibilizam informações sobre data de nascimento, fotografia e informações satisfatórias sobre a escolaridade de quase todos os eleitos, em outros websites praticamente inexistem informações sobre estes itens.

Apenas a título de exemplo, como pode ser observado pelos dados contidos na tabela acima, as casas legislativas examinadas disponibilizam fotografias sobre quase a totalidade de seus integrantes, o que pode servir como uma fonte eficaz para a caracterização de variáveis importantes, tais como cor da pele. Por sua vez, o percentual mais baixo foi obtido pela Assembleia Nacional Venezuelana, com $88,6 \%$ de seus parlamentares disponibilizando foto na internet durante o período da pesquisa.

Já as informações sobre outras dimensões do perfil social dos parlamentares, tais como data de nascimento, escolaridade e, especialmente, atividades profissionais, estão disponíveis de maneira bem mais reduzida. Com efeito, a partir da consulta aos websites das casas legislativas dos países analisados, é possível obter informações sobre a data de nascimento de apenas 60,5\% de seus parlamentares, sendo que os maiores e menores percentuais são obtidos, respectivamente, pela Câmara dos Deputados brasileira $(99,2 \%)$ e pelas assembleias da Argentina $(14,5 \%)$ e Venezuelana $(14,5 \%)$, com percentuais bastante inferiores de seus parlamentares disponibilizando

\footnotetext{
${ }^{9}$ Não se deve confundir os websites institucionais com as páginas de perfis dos parlamentares contidas nas casas legislativas, pois aqueles se constituem domínios próprios dos parlamentares hospedados nas casas legislativas, enquanto as páginas de perfis oferecem apenas as informações-padrão e dados biográficos sobre os membros do parlamento. Sublinhe-se que apenas estas fontes utilizadas durante a coleta de dados para a construção das planilhas constituem a base de dados da presente pesquisa. A partir do próximo capítulo, procederemos a uma avaliação mais sistemática dos websites dos deputados e senadores dos países mencionados.
} 
informações sobre a data de nascimento. Quase o mesmo padrão é seguido pelas demais variáveis de perfil social, tais como escolaridade e exercícios de atividades profissionais.

Passemos agora a uma análise comparativa mais detalhada das informações disponíveis nos websites das casas legislativas mencionadas sobre as três dimensões do perfil e do comportamento político das elites parlamentares que integram estas casas.

\section{ANÁLISE DOS WEBSITES DOS ORGÃOS LEGISLATIVOS}

No tocante à análise dos websites legislativos, procuraremos utilizar como parâmetro para a avaliação das informações disponíveis sobre as elites parlamentares uma ficha para acompanhamento da atuação parlamentar elaborado por nosso grupo de pesquisa por ocasião do funcionamento do programa Vigilantes da democracia, dentro das atividades do convênio entre a UFPR (Universidade Federal do Paraná) e a FIEP (Federação das Indústrias do Estado do Paraná) inserida em anexo ${ }^{10}$. Assim procedemos porque, a nosso ver, essa dimensão mais "informacional" do uso da web pelos atores políticos tem sido frequentemente negligenciada nos estudos sobre o uso da internet por parte dos vários segmentos das elites políticas os quais tendem a se concentrar mais nos mecanismos de "participação e interação" política disponibilizados pela internet, subestimando frequentemente essa dimensão informacional, também relevante para uma maior transparência da atuação das elites parlamentares e agregação de accountability nas relações de representação.

\section{PERFIL SOCIAL E BIOGRÁFICO DOS PARLAMENTARES}

A primeira dimensão de nossa análise consiste no grau de presença nos websites nos órgãos legislativos de informações que nos permitam identificar os "atributos inatos" e "adquiridos" dos deputados e senadores. Como variáveis importantes para a identificação dos "atributos inatos" das elites parlamentares (ou seja, aqueles atributos que independem dos processos de socialização e de adaptação diferenciais dos quais foram objetos e agentes os próprios deputados a partir da data de

\footnotetext{
${ }^{10}$ Quando as informações contidas nos portais das casas legislativas fossem consideradas confiáveis e satisfatórias para o preenchimento dos itens contidos na ficha, computamo-las como "informações satisfatórias" (IS) sobre determinado item ou variável.
} 
seu nascimento), destacamos as seguintes: nome e profissão dos pais ou chefes de família; data de nascimento; cor da pele e local de nascimento. Como "atributos adquiridos" pelos parlamentares a partir de sua socialização na infância podemos mencionar: religião, escolaridade, estado civil e atividades profissionais.

Todas estas são informações relevantes para o conhecimento de quem decide, ou seja, as características dos atores que tomam as decisões nos órgãos parlamentares, assim como apreender a dimensão mais "societal" da atividade política destes atores, dimensão esta frequentemente negligenciada nos estudos empreendidos sob a influência da escola neo-institucionalista.

As médias dos índices de desempenho das informações sobre o perfil social dos deputados são dadas pelo gráfico abaixo. Foram desconsideradas em nossa pontuação aquelas variáveis cuja frequência observada fosse próxima de zero.

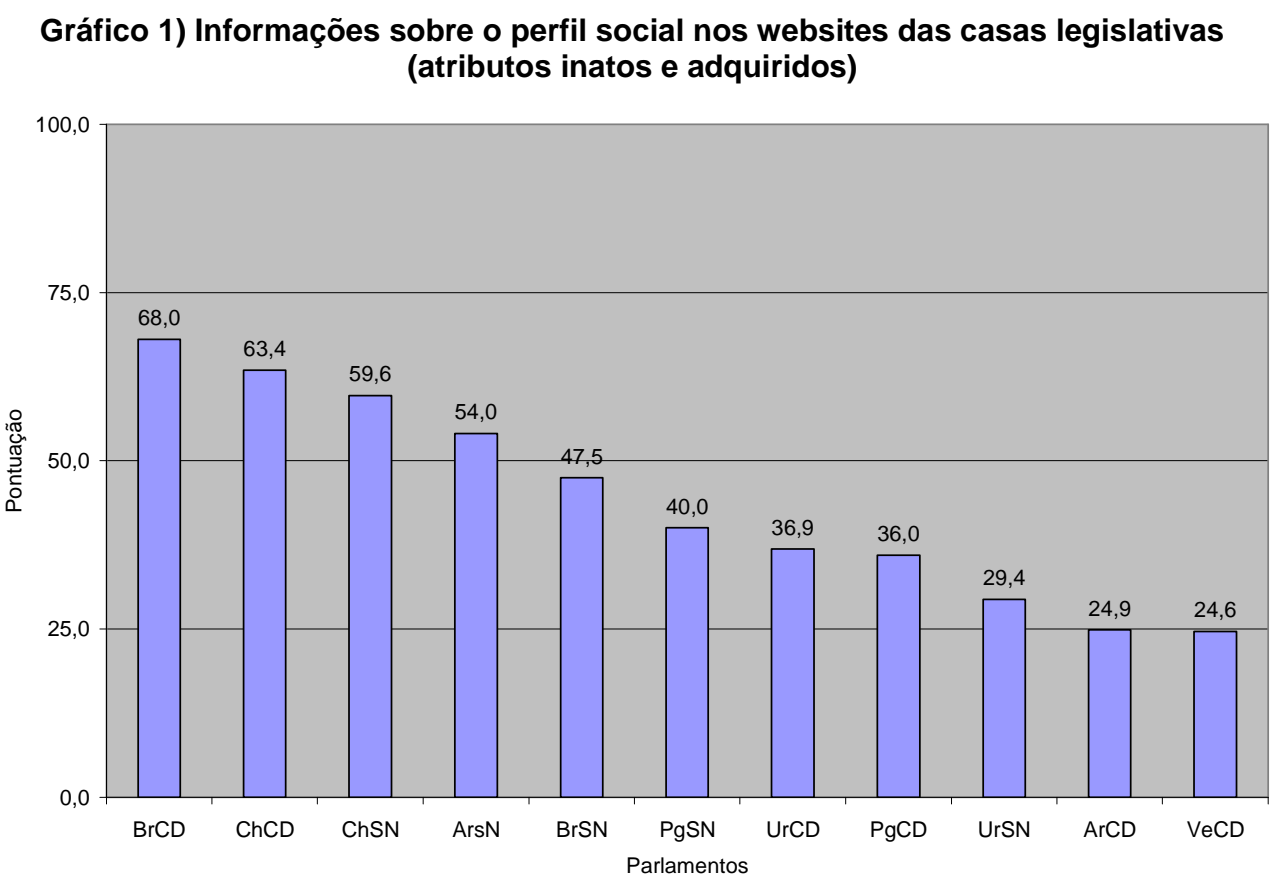

Fonte: Elaboração da autora

Podemos observar uma distribuição bastante desigual do grau de transparência das informações sobre os perfis parlamentares contidas nas várias casas legislativas. Enquanto alguns parlamentos apresentaram graus satisfatórios de disponibilidade de informações sobre dimensões tais como data de nascimento, fotografia do parlamentar, grau de escolaridade e sobre as atividades profissionais exercidas pelos deputados e senadores que dela fazem parte, tal como a 
Câmara dos Deputados brasileira e chilena, por exemplo, o destaque negativo ficou com as casas legislativas da Argentina (Câmara dos Deputados) e a Assembleia Nacional da Venezuela, com percentuais bastante inferiores de informações sobre o perfil social de seus deputados.

Pelo gráfico acima, podemos observar que apenas quatro casas legislativas apresentam um grau de transparência satisfatório (i. e. acima da média) no tocante à disponibilização de informações sobre suas elites parlamentares (Br/CD; Ch/CD; Ch/SF; Ar/SN). As demais casas legislativas apresentam informações insatisfatórias sobre o "perfil social" dos deputados. Não por acaso, o site que apresentou melhor desempenho foi justamente aquele que adotou formuláriospadrão para a apresentação de informações básicas sobre seus deputados, como foi o caso da Câmara dos Deputados brasileira, que adota uma forma razoavelmente sistemática de apresentação dos dados dos parlamentares. Devido a isso, as informações básicas sobre os atributos inatos e adquiridos dos parlamentares são facilmente acessíveis a qualquer cidadão-internauta.

\section{TRAJETÓRIA POLITICA DOS DEPUTADOS E SENADORES SUL-AMERICANOS}

Nesse segundo item avaliamos o grau de presença de informações sobre a trajetória ou socialização política pregressa dos deputados e senadores. Nos estudos sobre recrutamento, via de regra a categoria de "socialização política" é empregada para designar itens relacionados à atividade política dos parlamentares antes do exercício do mandato parlamentar (Marenco, 2000, Marenco \& Serna2007).

Na dimensão "trajetória política" dos parlamentares incluímos itens tais como: "informações satisfatórias" (IS) sobre via de entrada na política; informações satisfatórias sobre período de entrada na política; local de entrada na política; qual o primeiro mandato parlamentar exercido; destaques para mandatos legislativos anteriormente exercidos; IS sobre cargos administrativos anteriormente ocupados; informações sobre vínculos com associações ou "capital social”, e outras variáveis relevantes empregadas em estudos sobre recrutamento e perfil sociopolítico das elites parlamentares.

Como no item anterior, derivamos como corolário do trabalho de coleta de dados um índice que consiste no percentual de informações contidas sobre os parlamentares nos sites legislativos. Optamos por não inserir nenhum fator de ponderação em nosso índice, objetivando simplificar o processo de análise de dados. O desempenho de cada assembleia em relação às informações mais ou menos satisfatórias sobre a trajetória política de seus parlamentares é dado pelo gráfico abaixo: 
Gráfico 2) Informações sobre a trajetória política nos websites

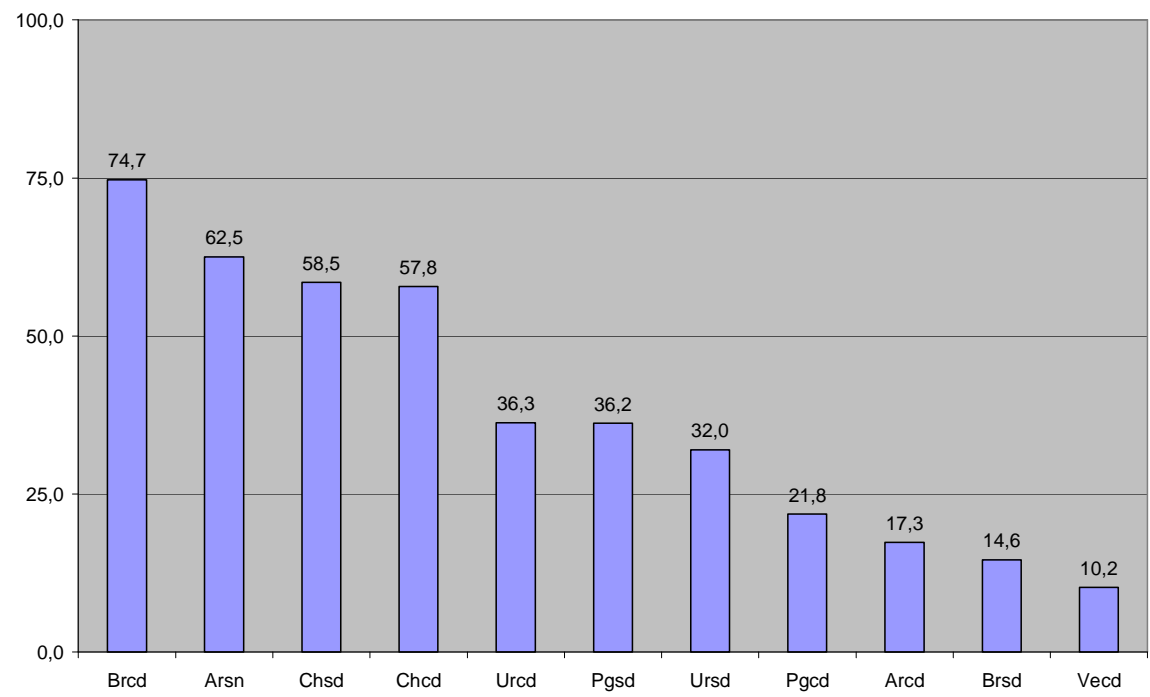

Fonte: Elaboração da autora

Pelo gráfico acima, percebe-se uma grande assimetria de informações quanto a este quesito, coexistindo websites parlamentares que apresentam um elevado grau de informações sobre a trajetória política anterior de seus representantes, como é o caso da Câmara dos Deputados e do Senado argentinos, ao lado de órgãos parlamentares extremamente frugais na disponibilização de tais informações, como é o caso da Assembleia Nacional venezuelana e do Senado brasileiro.

Também aqui as informações sobre a trajetória política e cargos anteriormente ocupados pelos parlamentares são bastante reduzidas e assimétricas, sendo na maior parte das vezes apresentada de forma incompleta, fragmentada e não sistemática. No entanto, por outro lado há um grupo de parlamentares que, pelo fato dos parlamentos disponibilizarem em seus sites formuláriospadrão com informações sobre a trajetória política obtiveram maior pontuação no tocante à transparência e disponibilização de informações, como foi o caso mais uma vez da Câmara dos Deputados brasileira e do Senado argentino ${ }^{11}$.

\footnotetext{
${ }^{11}$ Segundo informações disponibilizadas por funcionário do Comitê Gestor da Câmara dos Deputados, no início de cada mandato são aplicados questionários aos novos deputados empossados que servem de base para a confecção dos perfis que são disponibilizados no Portal da Câmara dos Deputados ao longo das legislaturas.
} 


\section{COMPORTAMENTO POLÍtico E USO DA WEB POR PARLAMENTARES DA AMÉRICA DO SUL}

Por fim, um outro nível de análise a ser trabalhado a partir das informações contidas nos websites das casas legislativas sul-americanas é o comportamento político dos deputados e senadores, que abrange variáveis como: disponibilização de e-mail; endereço do gabinete; informações constantes nos perfis sobre se possui ou não website pessoal ou institucional; telefone para contato; acesso rápido para diversos tipos de proposições sugeridas, tais como projetos de lei, requerimentos, emendas ao orçamento, discursos, votação nominal, presença em plenário, dentre outras informações que, embora aparentemente de interesse estrito aos especialistas ou daqueles diretamente envolvidos no trabalho legislativo, são de fundamental importância para agregar transparência e accountability aos trabalhos parlamentares (Norris, 2001; Beentham, 2006).

Neste ponto da exposição podemos colocar a indagação: qual o sentido de analisar a composição social dos diferentes segmentos das elites parlamentares? Tal estudo, a nosso ver, seria destituído de importância caso eventuais diferenças (de renda, status/classe social, patrimônio, nível educacional, perfil ideológico e trajetórias políticas, assim como eventuais processos de "ressocialização" devido às carreiras nas instâncias partidárias) não interferissem de alguma forma nas múltiplas dimensões do comportamento político dos parlamentares, gerando diferenças significativas nas diversas estratégias e padrões de comportamento observados dos mesmos nas várias esferas onde se dá sua atividade política e social. Sendo assim, também é de fundamental importância para o aprofundamento da democracia e para a agregação de accountability aos sistemas políticos que tais informações estejam disponíveis online, pois isso permite aos cidadãos ter acesso a informações não apenas sobre quem decide, mas também sobre o que se decide, ou seja, como os membros do parlamento estão se comportando durante o processo deliberativo sobre políticas governamentais e assuntos de interesse público.

O gráfico abaixo ilustra o grau de disponibilidade de informações relevantes para o estudo do comportamento político dos parlamentares nas casas legislativas, tanto através da visita aos perfis parlamentares dos próprios deputados, quanto através da visita aos websites das casas legislativas ${ }^{12}$.

\footnotetext{
${ }^{12}$ Para simplificar a exposição, unificamos no Gráfico 3 tanto as informações que podem ser acessadas diretamente a partir dos websites quanto informações que podem ser acessadas indiretamente, a partir dos portais das casas 


\section{Gráfico 3) Informações sobre o comportamento político dos parlamentares} nos websites parlamentares e nas casas legislativas

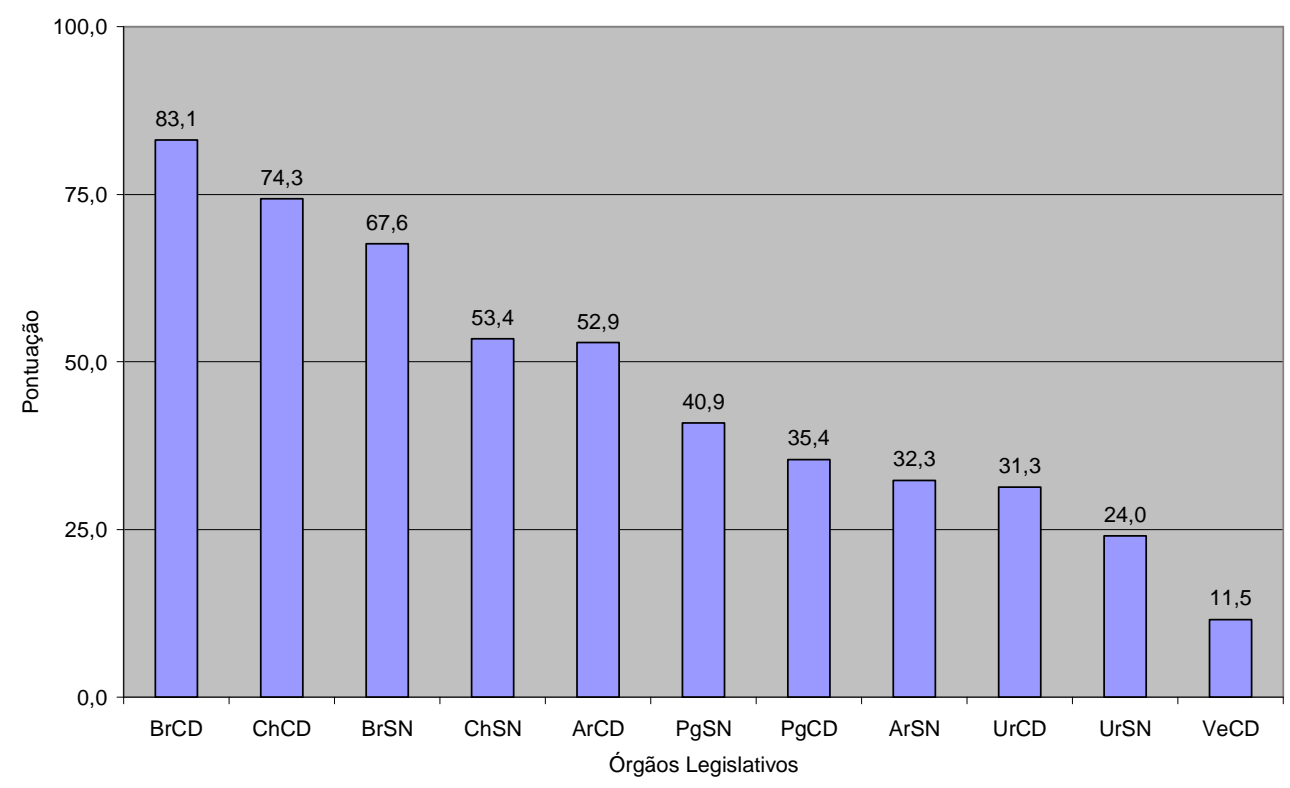

Fonte: Elaboração da autora

Apenas cinco assembleias atingiram níveis razoáveis de transparência, indicando que muitas informações básicas e elementares sobre a atuação dos deputados e senadores não estão à disposição da opinião pública e do cidadão para acesso rápido e eficiente na maioria destas casas legislativas. Mais uma vez, os destaques negativos no tocante à clareza e transparência de informações sobre o comportamento dos parlamentares foram os portais da Assembleia Nacional da Venezuela e da Câmara e do Senado dos países do Cone Sul, ficando os parlamentos do Brasil e do Chile com maior índice de desempenho.

\section{6. ÍNDICE DE TRANSPARÊNCIA DOS PARLAMENTARES}

Podemos agora encerrar essa análise da primeira dimensão do uso da internet pelas elites parlamentares dos países examinados, analisando os dados conjuntamente e abordando alguns problemas teórico-metodológicos relacionados à mensuração das informações contidas nos

legislativas, e desconsideramos aquelas variáveis para as quais os percentuais fossem nulos ou próximos de zero para todas as casas legislativas analisadas. 
websites legislativos sobre tais elites parlamentares. Essa preocupação com a "mensuração" das informações se corporifica na composição de um indicador sintetizando os dados anteriormente apresentados. A composição desse indicador será feita através da agregação dos percentuais de informação contidos sobre as elites parlamentares sul-americanas em suas casas legislativas. Assim, podemos elaborar um gráfico consolidando as informações existentes sobre o grau de informatização da ação dos parlamentares constantes nas casas legislativas dos websites parlamentares dos países mencionados, bem como tecer algumas considerações sobre o potencial de tais recursos para a dinamização da comunicação e da interação dos eleitos com seus representantes bem como para o controle e monitoramento mais eficaz destes por aqueles, estreitando os vínculos de representação entre ambos.

Em relação ao primeiro ponto, o "grau de transparência" dos legislativos examinados nos é informado pelo gráfico abaixo, que resume o tipo de informação existente sobre os parlamentares e cerca de 50 variáveis de perfil, trajetória e comportamento que empregamos para analisar os sites.

\section{Gráfico 4) Índice de transparência dos websites legislativos sul-americanos (maio/junho de 2009)}

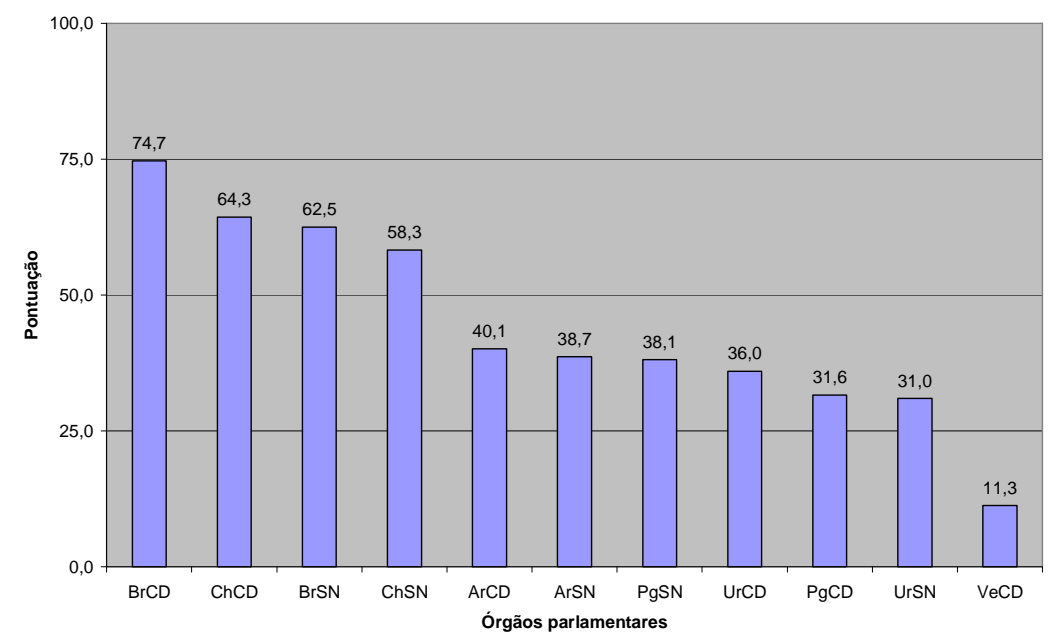

Fonte: Elaboração da autora

Pelo gráfico podemos observar a existência dos seguintes grupos diferenciados de sites legislativos, de acordo com o grau de transparência contido nestes sites sobre suas elites parlamentares: (1) parlamentos com grau satisfatório de informatização (tais como $\mathrm{BrCD}, \mathrm{ChCD}$, $\mathrm{BrSN}, \mathrm{ChSN}$ ), que apresentam um grau relativamente elevado de transparência sobre suas elites parlamentares; (2) casas legislativas com grau insatisfatório de transparência, tais como os demais 
órgãos parlamentares da Argentina, Paraguai, Uruguai; (3) websites com graus deficientes de transparência, como é o caso da Venezuela.

Sublinhe-se mais uma vez que, nessa análise abstraímos os aspectos qualitativos da organização das informações e dos recursos de mídia nessas casas legislativas. Deve ser mencionado, contudo, que algumas destas apresentam acesso bastante difícil e complicado a estes dados. Deve ser destacado mais uma vez que uma característica que singulariza o website da Câmara dos Deputados brasileira em comparação com os demais países examinados é a existência de um formulário contendo as informações padronizadas sobre os parlamentares, o que facilita sobremaneira a consulta do pesquisador a tais informações, bem como a interação do cidadãointernauta com seu parlamentar.

\section{CONSIDERAÇÕES FINAIS}

Podemos encerrar este artigo enunciando de maneira sistemática algumas conclusões gerais e inferências dos dados anteriormente apresentados. De uma maneira geral, ainda são bastante insatisfatórios e reduzidos os graus de transparência dos websites legislativos dos países sulamericanos pesquisados sobre várias dimensões do recrutamento e do comportamento de suas elites parlamentares. Apenas os websites de $\mathrm{BrCD}, \mathrm{ChCD}, \mathrm{BrSD}$ e $\mathrm{ChSD}$ podem ser considerados como tendo desempenho satisfatório a este respeito, e mesmo assim muito pode ser feito para melhorar a disponibilização de tais informações aos cidadãos.

No tocante ao uso de websites pelos membros das elites parlamentares sul-americanas, verificamos que ele é ainda irrisório em países mais próximos ao modelo das "democracias delegativas", com órgãos parlamentares fracamente institucionalizados, tais com PrCD, PrSN, e $\mathrm{VeCD}$, e que pudemos simultaneamente observar um esforço de institucionalização e aprofundamento das democracias parlamentares sul-americanas através dos recursos propiciados pela internet e pelos websites parlamentares.

Por fim, cabe esclarecer que as considerações acima foram uma tentativa inicial de efetuar um primeiro mapeamento da maneira pela qual as elites parlamentares examinadas estão utilizando a internet e do tipo de informação que pode ser encontrada nessas fontes. Observamos que, salvo em um ou outro website parlamentar isolado, ainda resta muito caminho a percorrer para que a internet se constitua numa fonte sistemática para o estudo das elites políticas, de natureza análoga à 
das demais, para não dizer de comunicação e interação entre representantes e opinião pública. Sendo assim, é indispensável que os analistas políticos e pesquisadores sobre as elites em geral e as elites parlamentares em particular desenvolvam instrumentos para avaliar e monitorar a quantidade e a qualidade das informações disponíveis em tais websites, para que estes divulguem informações sistemáticas e transparentes sobre os políticos, e não se convertam apenas em uma espécie de outdoor virtual dos deputados e senadores que agregue pouco valor às pesquisas sobre as elites e sistemas políticos e deixe de ser um instrumento de maior controle do cidadão-internauta sobre estas próprias elites.

\section{REFERÊNCIAS BIBLIOGRÁFICAS}

ANASTASIA, F., RANULFO, M., C., SANTOS, F.. Governabilidade e representação política na América do Sul. Rio de janeiro: Fundação Konrad Adenauer; São Paulo: Fundação Unesp, 2004.

BEETHAM, D.. Parliament and democracy in the twenty-first century: a guide to good practice. Geneva, Switzerland: Inter-Parliamentary Union, 2006.

BIMBER, B. DAVIS, R.. Campaigning Online. The Internet in U.S. Elections. New York: Oxford University Press, 2003

BRAGA, S. O papel das TICs na institucionalização das democracias; um estudo sobre a informatização dos órgãos legislativos na América do Sul com destaque para o Brasil. Brasília: Plenarium/CEDI, 2007. http://www2.camara.gov.br/internet/eve/realizados/portal_seminario2007/material.html. Acesso em: 25 de abril de 2007.

BRAGA, S., NICOLAS, M., A.. Prosopografia a partir da Web; avaliando e mensurando as fontes para o estudo dos deputados estaduais brasileiros na internet. In: Revista de Sociologia e Política, v. 16, p. 107-130, 2008.

KAKABADSE, A., KAKABADSE, N., KOUZMINA, A. Reinventing the democratic governance project information technology? A growing agenda for debate. In: Public Administration Review, v.63, n.1, p.44-60, 2003. 
LESTON-BANDEIRA, C.. Are ICTs Changing Parliamentary Activity in the Portuguese Parliament? In: The Journal of Legislative Studies, London, v. 13, n. 3, p. 403-421, sept. 2007.

MAINWARING, S.; SHUGART, M. Juan Linz, presidencialismo e democracia: uma avaliação crítica. Novos Estudos Cebrap, São Paulo, n. 37, $\quad$ nov. 1993. http://www.cebrap.org.br/imagens/Arquivos/juan_linz_presidencialismo.pdf

MARENCO, S.. Não se fazem mais oligarquias como antigamente: recrutamento parlamentar, experiência política e vínculos partidários entre deputados brasileiros (1946-1998). Tese (Doutorado) - Programa de Pós-Graduação em Ciência Política, UFRS/ IFCH, Porto Alegre, 2000.

MARENCO, S., SERNA, M.. Por que carreiras políticas na esquerda e na direta não são iguais. In: RBCS Revista Brasileira de Ciências Sociais, São Paulo, v. 22, n. 64, p. 93-113, jun. 2007.

NICOLAU, J.. Como Controlar o Representante? Considerações sobre as Eleições para a Câmara dos Deputados no Brasil. In: DADOS, Rio de Janeiro, Vol. 45, nº 2, pp. 219 a 236, 2002.

NORRIS, P. Digital divide; Civic Engagement, Information Poverty, and the Internet Worldwide. Cambridge: Cambridge University Press, 2001.

NORRIS, P. Preaching to the Converted? Pluralism, Participation and Party Websites. In: Party Politics, 9(1): 21-45, 2003.

OLIVEIRA, L. H. H.. Presidencialismos em Perspectiva Comparada. In: Dados. Rio de Janeiro, v. 49, p. 301-343, 2006.

RÖMMELE, A., Political Parties, Party Communication and New Information and Communication Technologies. In: Party Politics, 9:1, p.10, 2003

SCHUSSMAN, A., EARL, J.. From Barricades to Firewalls? Strategic Voting and Social Movement Leadership in the Internet Age. In: Sociological Inquiry, 74(4), p. 439-463, 2004.

SEIFERT, J., CHUNG, J. Using E-Government to Reinforce Government-Citizen Relationships: Comparing Government Reform in the United States and China. In: Social Science Computer Review, v. 27, n. 2, p. 3-23, 2009. 
SCHMITTER, P., C., KIES, R. MENDEZ, F., TRECHSEL, A.,H.. Evaluation of the use of new technologies in order to facilitate democracy in Europe. Luxemburg: Lars Bosche, 2003.

WARD, S., GIBSON, R., K., NIXON, P.. Parties and the internet: An overview. In R. K. Gibson \& P. Nixon \& S. Ward (Eds.), Political parties and the Internet: Net gain? London, Routledge, p. 937, 2003.

WEISSBERG, R.. Technology Evolution and Citizen Activism: The Net and the Rebirth of Limited Government. In: The Policy Studies Journal, 31(3), p.385-395, 2003.

WILliAMSON, A.. MPs online: Connecting with constituents. In: Hansard Society, London, 2009.

ZITTEL, T.. Political Representation in the Networked Society: The Americanization of European Systems of Responsible Party Government?. In: Journal for Legislative Studies, 9: 1-22, 2003. 
Anexo 1: Modelo de ficha biografia com informações básicas sobre elites parlamentares

\section{MODELO DE PERFIL PARLAMENTAR}

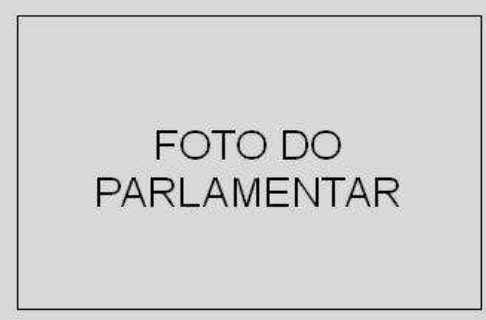

Nome completo:

Nome parlamentar:

Partido:

Gabinete:

Fone:

Email:

Website pessoal:

Nascimento:

Local de nascimento:

Estado Civil:

Profissões:

Filiação:

Escolaridade dos pais:

Profissão dos pais:

Estudos e Graus Universitários:

Atividades Profissionais:

Religião:

Forma de entrada na política:

Trajetória Política:

Legislaturas:

Filiações Partidárias:

Cargos executivos e administrativos ocupados:

Atividades Parlamentares na atual legislatura:

Vínculos com associações civis e políticas:

Atividade intelectual:

Total de votos:

Soma de receitas declaradas:

Soma das despesas declaradas:

Soma dos bens declarados: 


\title{
THE ELITE PARLIAMENTARY SOUTH AMERICAN AND \\ NTICs: PROFILE SOCIO-POLITICAL AND WEB USE BY REPRESENTATIVES AND SENATORS OF BRAZIL, ARGENTINA, CHILE, PARAGUAY, URUGUAY AND VENEZUELA
}

\begin{abstract}
The aim of this paper is to present the results of our research on Internet use by parliamentary elites who hold national legislative bodies in the period May-June 2009 in Brazil, Argentina, Uruguay, Venezuela, Paraguay and Chile. We collect data and analyze information about all the 1501 parliamentarians from six countries and 11 legislative houses. From the collected data, the availability of information on sociodemographic and political behavior is rather uneven across the different legislative houses, highlighting the portals of the Chambers of Deputies and the Senate of Brazil and Chile as those who scored the highest index performance at the expense of other countries.
\end{abstract}

Keywords: Internet and Politics. Parliamentary elites South American. Degrees of political representation. 